\title{
Influx Constant
}

National Cancer Institute

\section{Source}

National Cancer Institute. Influx Constant. NCI Thesaurus. Code C94915.

A fractional rate by which tracer leaves plasma and is being trapped in a cell. Commonly it is obtained from the slope of a Patlak plot, where it is the increase in tissue activity concentration normalized by plasma activity concentration that occurs in a unit of normalized time. 